\title{
ESTRUTURA DA CAMADA LIMITE ATMOSFÉRICA ACOPLADA A HETEROGENEIDADE SUPERFICIAL NO SUL DA AMAZÔNIA - EXPERIMENTO SAMBBA/2012
}

\author{
Thomas Kaufmann ${ }^{1,}$, Gilberto Fisch ${ }^{2}$ \\ ${ }^{1}$ Instituto Nacional de Pesquisas Espaciais (INPE) \\ ${ }^{2}$ Instituto de Aeronáutica e Espaço (IAE - DCTA) \\ *tsskfmn@gmail.com
}

\section{RESUMO}

Este estudo utilizou dados de dropsondagens realizadas durante o Experimento SAMBBA (setembro/outubro de 2012) na Amazônia. Os resultados preliminares mostram uma notável evolução da camada limite atmosférica (CLA) ao longo da heterogeneidade superficial, assim como na presença de nuvens.

\section{SUMMARY}

This study used dropsonde data from the SAMBBA field campaign (held during September/October 2012) in Amazonia. Preliminary results showed a remarkable evolution of the convective boundary layer (CBL) along surface heterogeneity, and in the presence of clouds.

\section{INTRODUÇÃO}

O Projeto South AMerican Biomass Burning Analysis (SAMBBA) [2] teve o objetivo de investigar as propriedades de poluição devido à queima de biomassa sobre a América do Sul e sua interação com a biosfera, o tempo e o clima amazônico. A campanha ocorreu durante o final da estação seca de 2012 (setembro/outubro), sendo que uma aeronave de pesquisa do UK Met Office [UK Facility for Airborne Atmospheric Measurement (FAAM) BAe-146] foi usada nas medições. Estudos recentes fornecem evidências da influência da heterogeneidade

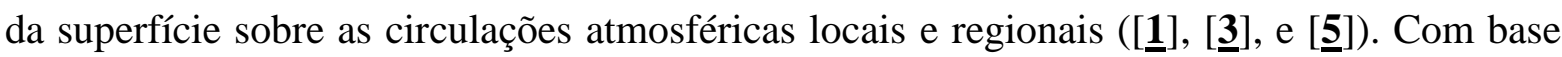
nisso, o objetivo deste trabalho é analisar a evolução temporal das propriedades da CLA durante um voo em específico (26 Set 2012), no qual a aeronave sobrevoou diferentes tipos de vegetação (heterogeneidade superficial). 


\section{MATERIAIS E MÉTODOS}

Durante o voo, dropsondas RD94 da Vaisala Oy (Finlândia) foram soltas de forma a obter medições de temperatura, umidade e velocidade e direção do vento. Da decolagem [13:00 UTC, Porto Velho ( $8^{\circ} \mathrm{S}, 64^{\circ} \mathrm{W}$ - sudoeste da Amazônia)] até o pouso [16:30 UTC, Palmas $\left(10^{\circ} \mathrm{S}, 49^{\circ} \mathrm{W}\right.$ - sudeste da Amazônia e centro da América do Sul)], sete dropsondas foram soltas ao longo do trajeto (às 13:17, 13:57, 14:20, 14:44, 15:07, 15:33 e 15:48 UTC). Perfis de razão de mistura e temperatura potencial também foram utilizados para caracterizar a espessura, a estrutura e a evolução temporal da camada de mistura.

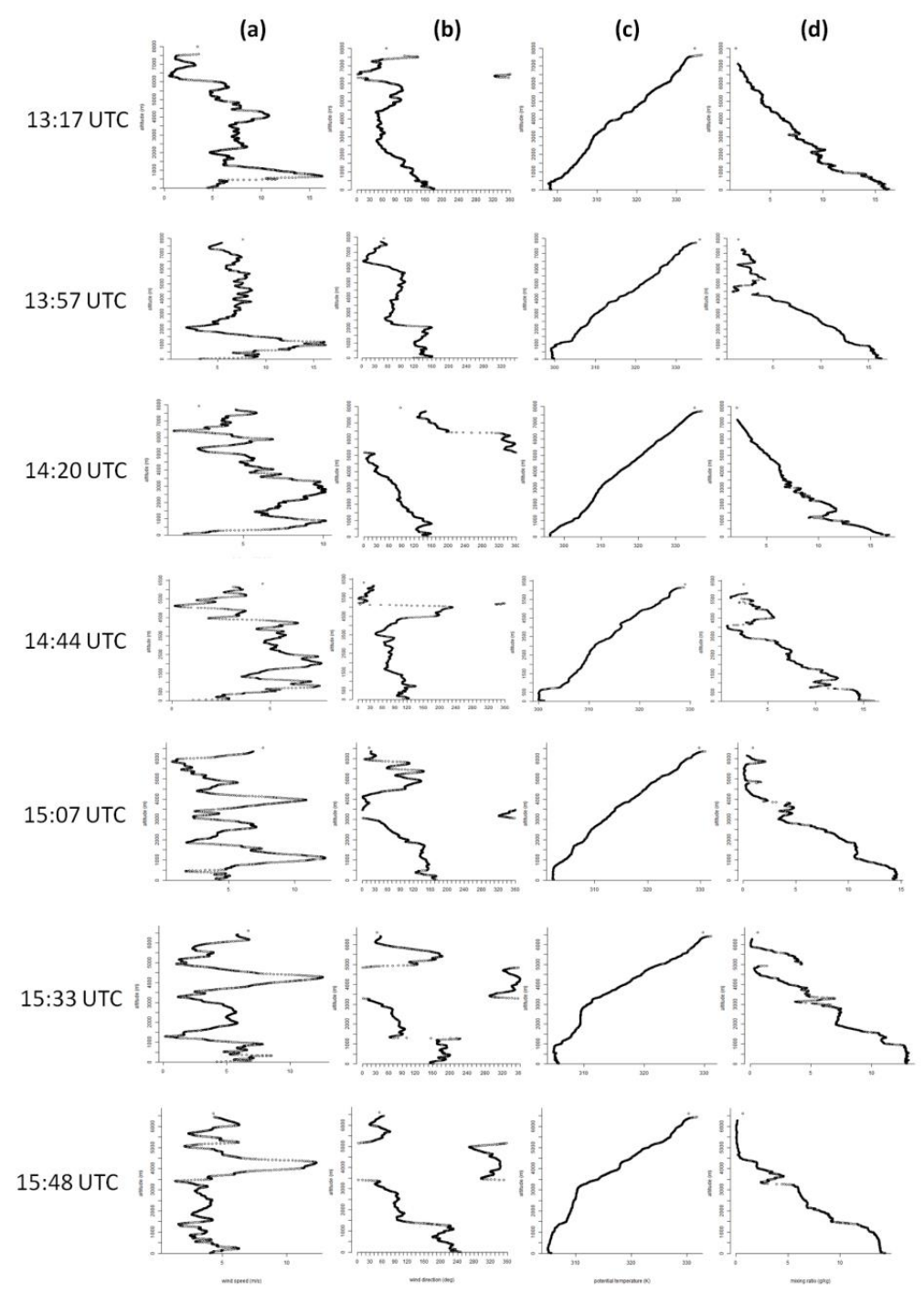

Figura 1 - Perfis verticais de (a) velocidade [m/s] e (b) direção do vento [graus], (c) temperatura potencial (K) e (d) razão de mistura [g/kg] para sete dropsondagens feitas durante o voo de 26 Set 2012 sobre o sul da Amazônia. 


\section{RESULTADOS}

$\mathrm{Na}$ área de decolagem, a CLA se apresentava bastante úmida (razão de mistura em torno de $15-16 \mathrm{~g} / \mathrm{kg}$ ) e fria (temperatura potencial média de cerca de $300 \mathrm{~K}$ ), espessura entre 500-700 m, bem como um máximo na velocidade do vento em baixos níveis (13:17 até 14:20, Figura 1a). Essas são características atmosféricas típicas sobre áreas de florestas tropicais entre 09:00-10:00 horário local (aproximadamente o horário de início da convecção local). Características similares foram encontradas por []ㅡ. Sobre a área de pouso, a CLA se apresentava mais aquecida com valores entre 305-306 K (Figura 1c). Ao mesmo tempo, a CLA tornou-se mais seca (razão de mistura de $13 \mathrm{~g} / \mathrm{kg}$ ) e sua espessura mais profunda (entre 10001200 m) (Figura 1d). Também foi observado um máximo na velocidade do vento na média troposfera (14:44 até 15:48, Figura 1a). Esse comportamento se deu devido ao aquecimento diurno natural, mas também devido à mudança de superfície/paisagem, o que, consequentemente, implicou em mudanças na intensidade dos fluxos de calor sensível e latente. O cenário ao longo do voo variou de floresta tropical (área de Porto Velho) a cerrado (área de Palmas). Durante todas as dropsondagens, os perfis de direção do vento mostraram giro com a altura no sentido anti-horário: de sudeste (entre a superfície e o topo da camada limite), de leste e então de norte-noroeste (acima do topo da camada limite) (Figura 1b). Imagens de satélite no canal infravermelho (fornecidos pela NOAA e pelo INPE) indicavam a presença de nuvens convectivas na área de voo. Nuvens cumulonimbus frequentemente influenciam as características médias da CLA (tanto nos seus estágios de desenvolvimento, maduro e dissipativo [4]), porém estudos futuros serão necessários para analisar esse tipo de evidências de mesoescala nos dados do SAMBBA.

\section{CONCLUSÕES}

Observou-se uma notável evolução da CLA convectiva ao longo da heterogeneidade superficial. No meio da manhã (horário local) sobre a área de floresta, a CLA tendeu a ser rasa, fria e úmida. Entre o início e o meio da tarde (horário local), já sobre a área de cerrado, a CLA se aprofundou e se tornou mais seca devido à mudança de paisagem. Pretende-se comparar os perfis obtidos de dropsondas com os de rawinsondas e medidas de fluxos de energia e analisar a influência dos processos de convecção e de nuvens, a fim de obter um melhor entendimento da estrutura da CLA durante o voo de 26 de setembro. 


\section{REFERENCIAS}

[1] BRUNSELL, N.A.; MECHEM, D.B.; ANDERSON, M.C. (2011) Surface heterogeneity impacts on boundary layer dynamics via energy balance partitioning. Atmospheric Chemistry and Physics, 11: 3403-3416.

[2] SAMBBA [Coe. H] (2012). SAMBBA - The South AMerican Biomass Burning Analysis (SAMBBA). British Atmospheric Data Centre. Available from http://badc.nerc.ac.uk/data/sambba/

[3] SHAO, Y.; LIU, S.; SCHWEEN, J.H.; CREWELL, S. (2013) Large-Eddy AtmosphereLand-Surface Modelling over Heterogeneous Surfaces: Model Development and Comparison with Measurements. Boundary Layer Meteorology, 1-24.

[4] STULL, R. (1988) An Introduction to Boundary Layer Meteorology. Kluwer - Academic Publishers, 666p.

[5] SÜHRING, M.; RAASCH, S. (2013) Heterogeneity-induced heat-flux patterns in the Convective Boundary Layer: Can they be detected from observations and is there a Blending Height? - A Large-eddy Simulation study for the LITFASS-2003 Experiment. Boundary Layer Meteorology, 1-23. 